Revistade
Economild
Contemporâned

\title{
CADEIAS GLOBAIS DE VALOR, INOVAÇÃO E UPGRADING: ESTUDO SOBRE EMPRESAS INDUSTRIAIS ARGENTINAS COM BASE EM MICRODADOS
}

\author{
Mario Augusto Gouvêa Almeida ${ }^{a}$ \\ Hoyêdo Nunes Lins ${ }^{b}$ \\ Eva Yamila da Silva Catela
}

aAuditor Federal de Finanças e Controle da Secretaria do Tesouro Nacional. Florianópolis, SC, Brasil. ORCID: http://orcid.org/0000-0003-3621-5532.

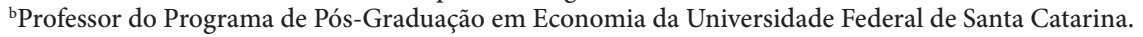
Florianópolis, SC, Brasil. ORCID: https://orcid.org/0000-0001-7438-2951.

'Professora do Programa de Pós-Graduação em Economia da Universidade Federal de Santa Catarina. Florianópolis, SC, Brasil. ORCID: https://orcid.org/0000-0002-5973-3116.

\section{Recebido em 04 dezembro 2018 \\ Aceito em 14 outubro 2019}

RESUMO: É crescente o interesse pelo debate sobre cadeias globais de valor (CGV), sobretudo com respeito às possibilidades dos países que adentram a órbita dessas estruturas. Inspirado nessa discussão, o artigo focaliza a inserção de firmas industriais argentinas em CGV utilizando microdados da Encuesta Nacional de Dinámica de Empleo e Innovación (ENDEI). O texto inicialmente discute as relações envolvendo as CGV, os estágios produtivos dos países implicados e o problema da inovação, e posteriormente olha para a indústria argentina conforme permitido pela referida base de dados. Os resultados confirmam, para Argentina, as postulações trazidas pela literatura sobre o perfil de envolvimento de economias de renda média em CGV. Notou-se entre as firmas argentinas algum dinamismo exportador em setores de alta e média/alta tecnologia, mas prevalecendo uma inserção baseada em montagem e processamento, com endogeneização tecnológica limitada.

PALAVRAS-CHAVE: cadeias globais de valor; inovação; Argentina; empresas industriais.

CLASSIFICAÇÃO JEL: F02, F60.

Correspondência para: Mario Augusto Gouvêa Almeida

Contato: mmarioaga@gmail.com 


\title{
GLOBAL VALUE CHAINS, INNOVATION AND UPGRADING: A MICRODATA BASED STUDY OF ARGENTINIAN INDUSTRIAL FIRMS
}

\begin{abstract}
The debate on global value chains (GVC) has gained momentum recently, especially concerning the advantages and drawbacks for the countries that enter their orbit. Inspired by this discussion, this article examines the insertion of Argentine industrial firms in GVC using microdata from the Encuesta Nacional de Dinámica de Empleo e Innovación (ENDEI). The text begins with a discussion on the relations involving GVC, productive stages of the participating countries and the issue of innovation, and then looks at the Argentine manufacturing sector as allowed by the database. The results confirm, for Argentina, the postulations brought by the literature on the involvement profile of middle-income economies in CGV. Among the Argentine firms comprised in this database, some export dynamism has been observed in high and medium / high technology sectors, but an insertion based on assembly and processing, with limited technological endogenization, has prevailed.
\end{abstract}

KEYWORDS: global value chains; innovation; Argentina; manufacturing companies. 


\section{INTRODUÇÃO}

A fragmentação internacional da produção industrial em cadeias globais de valor (CGV) ganhou terreno nas últimas décadas. Um reflexo refere-se ao reposicionamento de vários países em desenvolvimento na economia mundial, ampliando sua participação no comércio nessa escala. Também cresceu a presença de bens intermediários nas transações, indicando o importante papel das importações (ao lado do das exportações) nas redes de produção, no que diz respeito ao crescimento econômico e à geração de empregos.

As economias dos países em desenvolvimento não deixaram de repercutir esses processos. Em algumas, a participação em CGV ajudou o crescimento do produto e das exportações, representando ganhos de curto prazo. Em outras, ocorreram movimentos rumo a estágios produtivos mais elevados, significando mudança estrutural e ganhos de longo prazo. Compreender como as empresas de um país participam de CGV, considerando o estágio produtivo da economia nacional, constitui, assim, assunto importante na área do desenvolvimento econômico. Questões como armadilha da renda média, mudança estrutural e crescimento de longo prazo têm lugar nesse tipo de estudo.

Pretende-se neste trabalho abordar a inserção de empresas industriais argentinas em CGV. Sua base são os microdados da pesquisa ENDEI - Encuesta Nacional de Dinámica de Empleo e Innovación (ARGENTINA, 2015a), para o período de 2010 a 2012 e com amostra - estratificada por setor e por tamanho - de 3.691 empresas da indústria de transformação, pertencentes a universo de 15.368. Considera-se que o estudo se soma ao esforço de investigação, envolvendo diferentes instituições e pesquisadores, sobre a participação de países latino-americanos na dinâmica das CGV, conforme ilustrado por Prochnik (2010). O trabalho haverá de representar contribuição nesse esforço, apresentando uma abordagem não usual, que procura explorar a inserção em CGV por meio de informações de microdados ao nível da firma, a partir de uma base de dados ampla, atualizada e rica sobre a realidade industrial da Argentina.

A estrutura do texto exibe na próxima seção uma revisão bibliográfica sobre as relações entre participação de países em CGV, estágios produtivos e inovação. Depois se apresentam os procedimentos adotados na realização do estudo, informando sobre as hipóteses norteadoras, os dados e a metodologia utilizada. Em seguida aparece a análise propriamente dita, com as estatísticas descritivas e a abordagem econométrica empregada. A última parte traz algumas considerações finais. 


\section{CADEIAS GLOBAIS DE VALOR, ESTÁGIOS PRODUTIVOS E INOVAÇÃO}

Diversos estudos contemporâneos sobre o comércio baseado na distribuição internacional de atividades produtivas remetem às cadeias globais de valor (CGV). Na correspondente literatura, a produção (bens intermediários e finais) é apresentada como geograficamente fragmentada (entre países ou regiões) e com a localização determinada pelas vantagens comparativas para cada etapa do processo produtivo, ou, na formulação de Bhagwati e Dehejia (1993), pelas “vantagens comparativas caleidoscópicas".

Para Timmer et al. (2013), a fragmentação produtiva expandiria as oportunidades e ampliaria os benefícios para os envolvidos no comércio. Todavia, nem todos usufruem do mesmo modo: as várias etapas dos processos produtivos representam diferentes níveis de agregação de valor, e sua separação permite que os países tentem capturar valor adicionado (VA) em fases específicas.

\subsection{CADEIAS GLOBAIS DE VALOR E POSSIBILIDADES DOS PAÍSES}

Autores como Baldwin (2011) entendem que mesmo países menos desenvolvidos podem se beneficiar das CGV. A razão é que tais estruturas acenam com a presença em mercados praticamente inacessíveis de outra forma, ainda que os investimentos associados não sejam realizados durante longos períodos. As CGV representam opções também devido ao problema das dificuldades para transferir conhecimento tácito, conforme abordado no Atlas de Complexidade Econômica (HAUSMANN et al., 2011). Para países pouco industrializados, a inserção em CGV pode representar uma alternativa mais rápida para aceder ao conhecimento, comparativamente à estratégia de substituir importações, que procurava internalizar a produção de mercadorias consumidas localmente.

No período atual, de marcada fragmentação produtiva internacional, a participação de países menos desenvolvidos em CGV pode lhes representar uma expansão industrial mais acelerada e facilmente atingida, comparativamente ao observado em experiências anteriores. Contudo, como adverte Baldwin (2011, p. 33, tradução nossa), “[...] mais fácil e mais rápido não significa necessariamente melhor”. Tendo em vista as características da internacionalização das atividades de várias empresas de países centrais, o crescimento industrial suscitado pode se referir a um pequeno fragmento (ainda que sofisticado, eventualmente) do processo produtivo de uma mercadoria, transferido junto com o que o autor designa como empréstimo de tecnologia. Em suma, tratar-se-ia de um processo bem diferente do que prevalecia até algumas décadas 
atrás, quando “[...] uma nação tinha que ter uma profunda e ampla base industrial antes que pudesse exportar [...]" (BALDWIN, 2011, p. 33, tradução nossa).

Nesse sentido, se a fragmentação das atividades favorece a inserção daqueles países nos processos produtivos, cabe indagar sobre as possibilidades ligadas a essa participação. Baldwin (2012)assinala que as etapas geradoras de maior valor agregado (VA) nas atividades das CGV referem-se aos estágios pré e pós-fabricação - concepção, design, pesquisa e desenvolvimento (P\&D), vendas, marketing e serviços pós-venda -, indicando na chamada "curva sorriso" (smile curve) os diferentes níveis de criação daquele valor. O maior VA dessas etapas reflete as habilidades necessárias às atividades que geram produtos diferenciados. Contudo, há marcadas diferenças entre essas atividades quanto à criação de VA.

A Figura 1 mostra a adaptação efetuada por Corrêa, Pinto e Castilho (2017) na "curva sorriso" de Baldwin (2012), indicando, além das diferentes condições das atividades da cadeia para gerar valor, as etapas do fornecimento de matérias primas e da produção de partes e componentes. A primeira registra baixa capacidade para criar VA, de modo semelhante às atividades de montagem/processamento do produto final; a segunda abriga maior potencial de VA, devido ao incrustado conteúdo tecnológico, com o conhecimento associado.

É também importante destacar, sobre essas configurações da "curva sorriso", que em Baldwin (2012) há uma visão mais geral sobre o VA criado em cada segmento. Sua versão reflete o que se percebia entre os anos 1970 e 1990 sobre a expansão dos serviços, relativamente às atividades de manufatura. De mesmo modo, essa curva não considera o fornecimento de insumos e matérias primas, uma esfera de atividades de grande importância quando se trata de observar a geração de VA em países como Argentina ou Brasil. A versão apresentada em Corrêa, Pinto e Castilho (2017) leva em conta esse aspecto ao incluir o fornecimento de matérias primas, o processamento e a montagem final de produtos como atividades de menor VA na cadeia. Nos movimentos da economia mundial nas últimas décadas, essas atividades vêm sendo deslocadas para países em desenvolvimento, um processo que tem no Brasil, no México e na Argentina eloquentes ilustrações latino-americanas.

Ainda no tocante às possibilidades para os países, a abordagem das CGV salienta duas questões importantes ao focalizar os desdobramentos da fragmentação geográfica das redes de produção: de um lado, a governança exercida em escala de cadeia, salientando o modo como as firmas líderes interagem com outras empresas; de outro lado, as políticas executadas nos países em desenvolvimento com vistas ao upgrading de suas posições na economia global (GEREFFI e STURGEON, 2013; GEREFFI, 2001).

Sobre a governança, cabe assinalar que a posição de uma empresa na sua rede de vínculos define os benefícios da participação. Uma posição central representa 
competências e recursos dificilmente replicáveis pelos competidores, permitindo coordenar diversas atividades e funções rumo a um mesmo objetivo. Desta forma, a captura do valor dependeria das diferentes posições das firmas nas estruturas de produção e distribuição das CGV.

\section{Figura 1 - A "curva sorriso": versão original (A) e versão adaptada (B)}
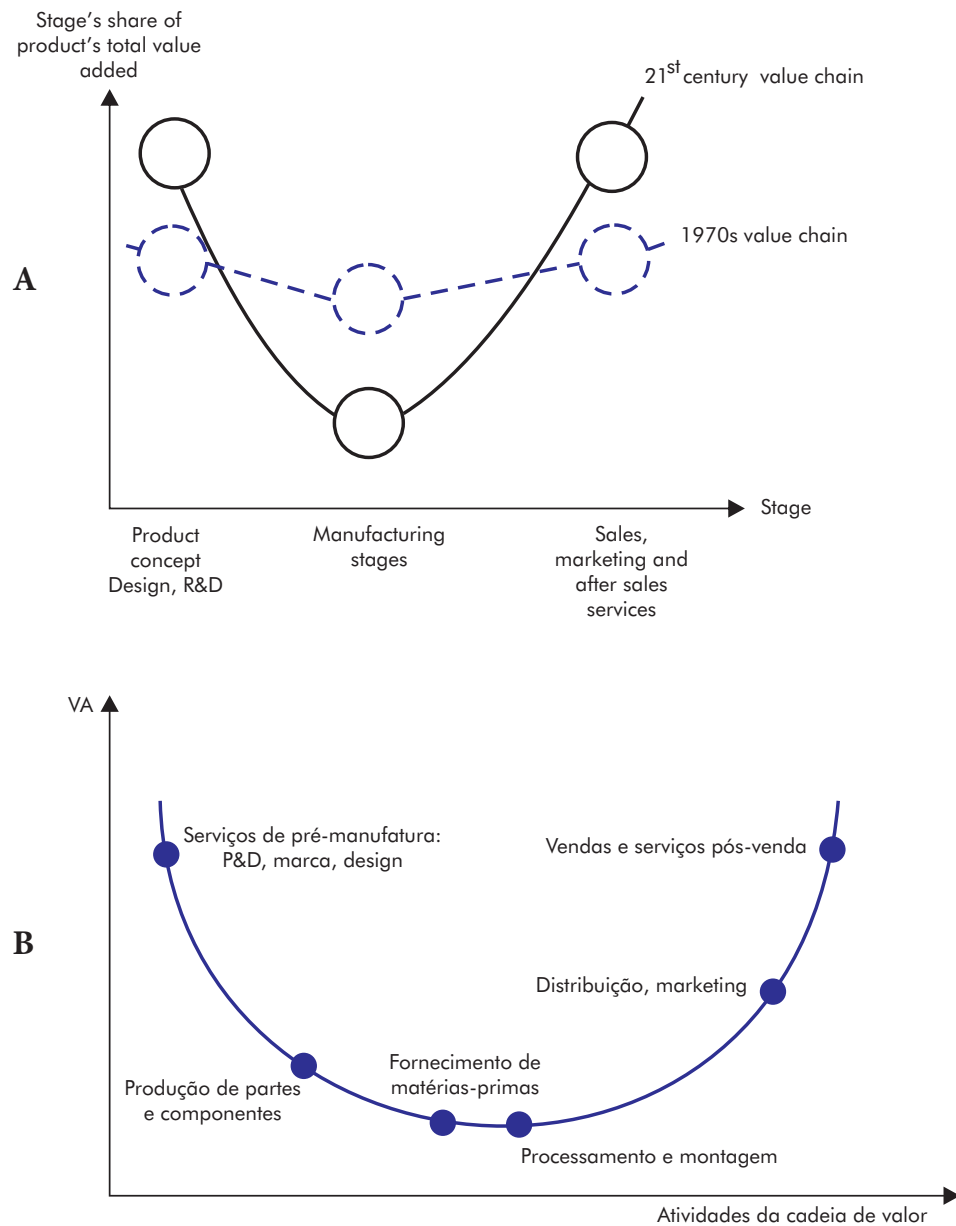

Fonte: Baldwin (2012) para A; Corrêa, Pinto e Castilho (2017) para B.

Se a posição da firma nas CGV é importante na definição do VA gerado, também fundamental é a natureza da governança de uma determinada CGV. Nesse sentido, ressalte-se a contribuição de Gereffi, Humphrey e Sturgeon (2005), os quais identificam diversos modelos de governança nessas estruturas, considerando notadamente a 
complexidade das transações no seu interior, o grau de codificação do conhecimento gerado e movimentado e a capacitação dos fornecedores. Nesse conjunto, estabelecem que, numa ponta, figura a governança por meio do mercado, mais provável quando as especificações dos produtos são simples e codificáveis (o que dificulta a acumulação de ativos específicos por algum participante) e não há requisitos sofisticados na capacitação dos fornecedores. No outro extremo, perante a ausência de codificação das especificações de produto, a complexidade dos produtos e o alto custo ou risco da capacitação de fornecedores, os autores consideram que a cadeia tende a se apresentar hierarquizada, com integração vertical.

Não obstante a sua variedade, as CGV ampliam as chances de participação de diferentes agentes nos processos produtivos e intensificam o comércio internacional de bens intermediários entre empresas e, também, intrafirma. Ao mesmo tempo, fazem crescer a competição internacional nas diferentes etapas produtivas, com reflexos na divisão internacional do trabalho (PINTO, FIANI e CORRÊA, 2017). Levando em consideração o debate conceitual sobre governança mencionado acima, não é de estranhar que, cada vez mais, os países em desenvolvimento atuem como fornecedores de matérias primas ou em processamento e montagem de produtos finais. Já os países desenvolvidos ampliaram sua participação em atividades de maior VA, como produção de peças e componentes de alta tecnologia; nos serviços, concentraram-se em segmentos intensivos em conhecimento, como criação de produto, design e P\&D (MEMEDOVIC e IAPADRE, 2009).

Essa clivagem remete à discussão sobre políticas governamentais para upgrading no envolvimento de países em desenvolvimento em CGV. Uma questão central, segundo Pinto, Fiani e Corrêa (2017), refere-se ao aumento do VA criado domesticamente, entendido como capaz de dinamizar as economias nacionais. Cabe sublinhar sobre isso que, em diversos países, a participação em CGV representa avanço industrial com reflexos de curto prazo na esfera das exportações, do emprego e da renda. Em alguns, os ganhos se estendem no longo prazo, pela maior atuação em segmentos geradores de efeitos de "transbordamento", inclusive para setores de maior sofisticação, aumentando a produtividade e contribuindo para o desenvolvimento nacional (UNCTAD, 2013; MEMEDOVIC e IAPADRE, 2009).

Para os países cujos benefícios restringem-se ao curto prazo, a mudança do padrão de especialização da economia pode limitar-se ao setor exportador, com poucos efeitos de encadeamento e escassa variação da produtividade. Nesses casos, a sofisticação das exportações não se reflete em melhora da estrutura produtiva, podendo inclusive caracterizar um aprisionamento em atividades de baixo VA. Um exemplo clássico refere-se à armadilha da renda média: ao atingirem um nível médio de renda, os países não conseguem avançar para estágios mais altos de desenvolvimento por deixarem de competir via preço com 
economias de baixa renda, devido aos seus maiores níveis salariais, e por não apresentarem condições para competir com economias mais avançadas (EICHENGREEN, 2011).

Portanto, a forma como os países exploram as possibilidades geradas pelas CGV afeta seus processos de desenvolvimento. $\mathrm{Na}$ base encontra-se a problemática do upgrading, a que Milberg e Winkler (2013) se referem como instrumento para, mediante movimentos objetivando uma maior captura de VA nas CGV, superar o padrão de especialização ditado pelas vantagens comparativas. Em alguns países, a atuação em cadeias restringe-se ao tipo de atividade desempenhado durante o próprio processo de inserção. Em outros, registra-se atuação mais abrangente e representativa de avanços em termos de, alternativamente ou não, maior eficiência produtiva (upgrading de processo), melhores produtos (upgrading de produto), direcionamento para cadeias de valor mais sofisticadas (upgrading de cadeia) e projeção rumo a atividades com maior intensidade de conhecimento (upgrading funcional). ${ }^{1}$

Essas modalidades de upgrading são sugeridas na adaptação efetuada por Corrêa, Pinto e Castilho (2017) na "curva sorriso" de Baldwin (2012), apresentada na Figura1. O upgrading funcional refere ao deslocamento na curva para atividades mais sofisticadas e de maior potencial para criar VA. Os outros três tipos se traduziriam em deslocamento da curva para cima, situação em que os países desempenham as mesmas atividades, mas é maior a captura de VA por conta de aumento da sofisticação em processo, produto ou cadeia. Os estágios produtivos referem-se à predominância de determinados setores nessas economias, com reflexo nas respectivas performances em emprego, produto, exportação e crescimento econômico (UNIDO, 2013).

É importante mencionar a ocorrência de casos de duplo upgrading, isto é, no interior de um mesmo setor, rumo a segmentos mais elevados, e envolvendo movimentos intersetoriais, atingindo-se setores representativos de maior valor agregado. Situações desse tipo foram detectadas por Lee, Szapiro e Mao (2017) em países asiáticos como Coréia do Sul e Taiwan. Segundo os autores, esses movimentos permitiram aos países registrar aumento no nível do seu VA industrial e, fazendo frente, dessa forma, à elevação dos salários domésticos, contornar o problema da armadilha da renda média.

\subsection{PERCURSOS NOS ESTÁGIOS PRODUTIVOS DAS CADEIAS GLOBAIS DE VALOR}

O problema relativo à passagem dos países pelos estágios produtivos das CGV é abordado por Corrêa, Pinto e Castilho (2017) tomando como ponto de partida a

\footnotetext{
1 Para o aprofundamento dos diferentes tipos de upgrading, consultar Pietrobelli e Rabellotti (2006) e Humphrey e Schmitz (2002).
} 
“curva sorriso" de Baldwin (2012). Nos estágios iniciais trata-se basicamente, nas estruturas produtivas, de manufaturas de baixa intensidade tecnológica e forte uso de mão de obra ou recursos naturais. Seu potencial para criar empregos é grande, embora de baixa qualificação, e sua contribuição ao fortalecimento do processo de crescimento industrial é considerável. Todavia, há limitações quanto à acumulação de capital, devido à reduzida intensidade tecnológica.

$\mathrm{O}$ avanço no estágio produtivo reflete-se em maior participação de manufaturas de média e alta intensidade tecnológica, prevalecendo, todavia, os níveis mais baixos nesse conjunto. $\mathrm{O}$ êxito induz à diversificação para segmentos mais sofisticados e rentáveis, em processo de progressivo aprofundamento rumo, por exemplo, às indústrias de equipamentos de transporte e eletrônicos. Indústrias intensivas em tecnologia empregam menos que as de baixa tecnologia, mas os empregos são mais qualificados. E, além da maior produtividade no próprio segmento, uma articulação significativa com atividades de outros setores pode representar "transbordamentos" e maior produtividade em termos gerais. Adicionalmente, nesse estágio, também serviços, exibindo pouca sofisticação e escasso conteúdo de conhecimento, podem ser fornecidos pelos países.

Nos estágios mais avançados figuram países em cujas estruturas produtivas prevalecem setores intensivos em conhecimento e tecnologia, como nas manufaturas associadas a máquinas e equipamentos eletrônicos e de transporte, e também serviços como em finanças, transporte e tecnologias de informação. Porém, a fragmentação produtiva internacional exibe especialização mais de atividades do que de setores; esses países restringem-se às atividades intensivas em conhecimento desses setores, que costumam gerar poucos empregos em termos relativos, embora utilizem mão de obra qualificada. A competitividade baseia-se em maior diferenciação e inovação, conforme a fronteira tecnológica existente, e a elevada produtividade e o grande potencial de "transbordamento" contribuem para uma maior taxa de acumulação de capital.

No tocante ao "percurso" dos países nas CGV, pode ocorrer evolução quando um país melhora seus processos produtivos ou seus produtos (upgrading de processo e produto). Também há evolução com respeito às atividades desenvolvidas (upgrading funcional), com migração para as de maior VA e maior intensidade em conhecimento, em um mesmo estágio produtivo.

Para países no primeiro estágio, a inserção nas CGV acontece geralmente em atividades de processamento, em segmentos manufatureiros intensivos em recursos naturais ou trabalho e de baixa intensidade tecnológica. As CGV nesses setores tendem a ser lideradas por compradores, no sentido de Gereffi (1994), que determinam as especificações dos produtos aos subcontratados. Também nesse estágio há países com atividades de serviços pós-manufaturas de menor valor adicionado ou com baixo nível 
de industrialização e abundância em recursos naturais (casos em que a participação em CGV é determinada pelo fornecimento dessas matérias primas). Apesar dos escassos encadeamentos, esse tipo de participação permite auferir retornos em emprego, renda e produtividade, impulsionando os respectivos processos de expansão industrial.

No segundo estágio produtivo, os países inserem-se em cadeias de maior aprisionamento tecnológico (eletrônicos, equipamentos de transporte), lideradas por produtores (conforme GEREFFI, 1994), com fornecimento pela firma líder dos insumos necessários (peças e componentes de alta intensidade tecnológica) à montagem dos produtos finais pelas contratadas. Embora em setores mais sofisticados tecnologicamente, a participação dos países ocorre em etapas como processamento e montagem, o que, de toda maneira, contribui para aumentar o emprego, a renda e a produtividade. Há também países em serviços representativos de baixo VA e outros que, não obstante um nível mais alto de industrialização, não atuam em segmentos mais complexos devido à limitação de suas estruturas tecnológicas, ao mesmo tempo em que, pelos níveis salariais maiores, não logram presença em processamento (armadilha da renda média). Assim, com abundância de recursos naturais, participam das CGV basicamente como fornecedores de matéria prima.

O terceiro estágio produtivo caracteriza o padrão de inserção dos países desenvolvidos, cuja atuação geralmente se traduz em "criação" de CGV, pois em regra o processo de fragmentação produtiva derivou de avanços tecnológicos e estratégias de grandes corporações sediadas nesses países. Essas empresas mantiveram centralizadas as suas atividades principais - o core business -, representativas de maior VA e distribuíram nos países em desenvolvimento as demais atividades, mormente as de maior intensidade em trabalho. Note-se que nesse estágio os países podem atuar em atividades de VA um pouco mais baixo, principalmente quando, embora atingindo esse terceiro patamar, apresentam nível de renda inferior.

Entretanto, a participação em CGV não se revela necessariamente um processo sequencial ou linear. Observando experiências asiáticas, na Coréia do Sul, em Taiwan e na China, Lee, Szapiro e Mao (2017) perceberam oscilações na adesão às CGV, conforme o nível de desenvolvimento industrial atingido. Os autores fazem referência a um encadeamento do tipo "in-out-in again”, quer dizer, a uma trajetória de maior ou menor participação em CGV refletida no grau de presença de valor adicionado estrangeiro nas exportações do país em questão. A lógica subjacente assim se apresenta:

- no início do processo de expansão econômica, caracterizado por baixo e baixomédio nível de renda, a relevância da aprendizagem junto a fontes de conhecimento externas torna importante uma maior integração à CGV, razão pela qual cresce a incidência do valor adicionado estrangeiro; 
- no estágio de médio e médio-alto nível de renda, tem lugar uma busca de upgrading funcional e setorial que rima com tentativa de independência vis-àvis às CGV existentes e externamente controladas, traduzindo-se essa separação em queda da participação do valor adicionado estrangeiro;

- no período de alta renda, as empresas surgidas mais recentemente podem ter que protagonizar maior abertura ao exterior, estreitando mais os seus vínculos em nível de CGV com vistas a fortalecer a sua capacidade de inovar, uma situação que faz subir a ocorrência do valor agregado estrangeiro.

Há, portanto, ao longo do tempo, uma espécie de movimento pendular entre participação (implicando maior adesão) em CGV e criação ou construção, pelas empresas, de cadeias de valor locais. Em outras palavras, oscila-se entre o controle ou a dominação externa e o, por assim dizer, exercício de poder internamente protagonizado.

\subsection{INOVAÇÃO COM VISTAS AO UPGRADING}

Como sugerido, posteriormente à inserção nas cadeias os países podem evoluir, em termos seja de upgrading de produto e processo ou de upgrading de cadeia e funcional. Quando ocorre "transbordamento" ligado ao movimento de endogeneização tecnológica, a evolução da estrutura produtiva do país tende a ser impulsionada (CORRÊA, PINTO e CASTILHO, 2017). Nesse caso, configurar-se-ia uma mudança estrutural, envolvendo o alcance de patamares produtivos mais elevados.

Portanto, as posições hierárquicas das firmas dos países em desenvolvimento no interior das cadeias guardam relação com os respectivos desempenhos em inovação tecnológica. Estes, por sua vez, espelham as condições locais, sobretudo para atividades mais sofisticadas. Humphrey e Schmitz (2000, 2002), investigando as possibilidades de upgrading em clusters industriais que participam de CGV, instalados principalmente em países em desenvolvimento, argumentam que saltos importantes (notadamente upgrading funcional) costumam depender do vigor inovativo local. Isso se mostraria como tendência não obstante ser diferenciada a maneira como os diversos clusters industriais se inserem em CGV - algo que envolve diferentes tipos de governança exercidos no interior de tais cadeias -, repercutindo nas possibilidades de upgrading local.

Nota-se ser central nesse debate o problema da inovação. Esta ocupa posição de grande destaque em abordagens sobre CGV como as apresentadas pela World Trade Organization, que se assinala, por exemplo, que “[a] natureza da tecnologia usada em produtos desempenha um papel maior na determinação da estrutura de governança de 
cadeias de valor e dos benefícios da participação de países em desenvolvimento" (DOLLAR, 2019, p. 4, tradução nossa). Rikap (2018) amplia o escopo da análise sobre o papel da inovação focalizando o elevado poder, nas relações em nível de cadeia, que o monopólio da inovação outorga às empresas líderes. "O grande gap entre as capacidades de inovação das firmas deixa aquelas não inovadoras sem qualquer opção melhor do que o aceite da subordinação [...]” (RIKAP, 2018, p. 69, tradução nossa). Mais do que isso: “[...] o efeito, em termos de diferenciação de longo prazo, da monopolização da inovação no interior de um ramo não pode ser negligenciado como explicação conceitual para a [própria] emergência de CVG, logo, das assimetrias estruturais de poder entre firmas" (RIKAP, 2018, p. 69, tradução nossa).

Ocorre, como enfatizam Viotti e Macedo (2003), entre outros, que inovar constitui prática de natureza coletiva. As empresas não inovam isoladamente e sim em meio a relações interempresariais amparadas por infraestrutura, pesquisa pública e privada e instituições como as de ensino e pesquisa - um conjunto que, permeado por um sistema normativo, forma o Sistema Nacional de Inovação (SNI), assunto sobre o qual autores como Nelson (1993) e Lundvall (1992), entre outros, constituem referências incontornáveis. Pietrobelli e Rabellotti (2006) salientam o quanto, em países em desenvolvimento, os SNI podem representar para o acesso ao conhecimento e o aprendizado e, assim, para o apoio à inovação nas firmas nacionais.

Assim, não há equívoco em considerar que existe espaço para férteis conexões analíticas entre a agenda de pesquisa sobre CGV e aquela relativa aos SNI, como assinalam Lundvall, Jurowetzki e Lema (2014, p. 31, tradução nossa).

O ponto principal na análise de CVG é que as transações ocorrem cada vez mais internacionalmente e, para uma firma de país em desenvolvimento, pode se mostrar útil aderir a uma CGV para elevar o nível (upgrade) de suas atividades. Essa é, obviamente, uma observação correta e relevante, que precisa ser considerada pelas empresas e pelas políticas e instituições de governos nacionais. O ponto principal na análise dos sistemas de inovação é, primeiro, que as empresas precisam construir capacidade interna (in house) para absorver o conhecimento vindo de fora, incluindo o que vem do exterior e de firmas líderes de CGV, e, segundo, que o contexto nacional importa para o modo como elas podem fazer isso.

Com efeito, tendo em vista as escalas de análise privilegiadas e os enfoques adotados, as duas abordagens podem ser vistas, em grande medida, como complementares no tocante à compreensão de importantes aspectos do desenvolvimento econômico na atualidade, assim como da sua promoção. Como sublinha Lundvall (2015), a pertinência da temática referente às relações entre CGV e SNI é sugerida pela própria observação do cenário internacional: mostraram-se bem sucedidos em processos de catching-up, relativamente ao nível dos países mais industrializados, aquelas economias em que se 
concedeu grande atenção, de forma paralela, à estruturação de SNI robustos e à participação em CGV. O autor ilustra essa postulação aludindo a experiências asiáticas, notadamente de Coreia do Sul, Japão, Taiwan e China.

De fato, desde o início dos anos 1990, numerosos estudos² sublinharam o caráter interdependente da inovação, assinalando que o conhecimento implicado é crescentemente multidisciplinar e de origem também externa à empresa. Nesse contexto, Chesbrough (2003) propõe falar em “inovação aberta”, tendo em vista que o respectivo processo se nutre de fluxos internos e externos de conhecimento e tecnologia, revelando-se estreitamente vinculado, portanto, à interação da empresa com atores externos.

Porém, a eficácia da "inovação aberta" exige das empresas o que Cohen e Levinthal (1990) denominaram "capacidade de absorção" (CA), definida pela habilidade da firma em reconhecer o valor da informação externa, assimilá-la e aplicá-la para fins comerciais. Sua base são os conhecimentos oriundos dos diferentes departamentos formais de $\mathrm{P} \& \mathrm{D}$, do ambiente de produção da firma ou simplesmente dos indivíduos que dela fazem parte.

A CA tende a se ampliar quando há modos de aprendizagem relacionados à maior intensidade de conhecimento tácito (implicando, principalmente, learning by using e by interacting) e à maior incidência de conhecimento codificado (vinculado ao chamado Science, Technology and Innovation mode), que inclui atividades de P\&D e interações com universidades e centros de pesquisa (JENSEN et al., 2007). Empresas com maiores CA são mais eficientes na exploração de conhecimento externo, melhorando o desempenho inovativo, como observado por Escribano, Fosfurie Tribó (2009) em conjunto de 2.265 firmas espanholas. Ebers e Maurer (2014) e Murovec e Prodan (2009), de sua parte, constataram que empresas com maior CA tendem a inovar mais em produto e processo. Também Laursen e Salter (2014) e Ince, Imamoglu e Turkcana (2016) detectaram o significado da CA para o processo de inovação.

Como a complexidade da inovação impõe usos cada vez mais frequentes de "inovação aberta", e a eficiência desta depende da CA inerente à empresa, cabe indagar sobre como as fontes externas de informação se relacionam e sobre as diferenças entre elas quando observadas pelo ângulo da firma. A literatura diz serem grandes as diferenças entre os parceiros envolvidos em cooperação no sentido indicado. As universidades e os institutos de pesquisa são reconhecidos como importantes fontes de oportunidades tecnológicas, pelo desenvolvimento de ciência básica e aplicada e o

2 Por exemplo: Carlsson (1997), Edquist (1997, 2005) Chesbrough (2003), Coombs, Harvey e Tether (2003), Malerba (2004, 2005), Tether e Metcalfe (2004), Asheim e Gertler (2005), Powell e Grodal (2005). 
treinamento de mão de obra qualificada (KLEVORICK et al., 1995). Hsieh, Ganotakis e Kafouros (2017) frisam que a cooperação com universidades é central nas inovações em produto, favorecendo novas formas de participação do mercado, inclusive mediante abertura de novos segmentos (BELDERBOS et al., 2004; MENTION, 2011).

Ao menos em parte, isso se relaciona à presença nas universidades de laboratórios de pesquisa especializados não disponíveis nas empresas. Com cientistas altamente qualificados, as universidades desenvolvem conhecimentos teóricos, enquanto as empresas se concentram em conhecimento aplicado (BSTIELER, HEMMERT e BARCZAK, 2015). Porém, é a combinação de ambos que pode propiciar inovações radicais (UN e ASAKAWA, 2015; WIRSICH et al., 2016), razão pela qual a colaboração universitária sobressai no processo de inovação e no upgrading tanto de cadeia como funcional.

Por outro lado, a colaboração com consultores e institutos de pesquisa privados tende a favorecer inovações incrementais, como assinalam Hsieh, Ganotakis e Kafouros (2017). Os consultores ajudam as empresas a inovar, mas sem envolver, em geral, o desenvolvimento de novas tecnologias; sua atuação favorece o acesso a ideias, tecnologias e conhecimentos acumulados pela observação em diferentes empresas e locais. A colaboração permite aos consultores transferir conhecimento de um contexto para outro, adaptando-o conforme as necessidades de cada empresa. Tal processo pode mostrar associação com o upgrading de processo e oupgrading de produto.

\section{PROCEDIMENTOS ADOTADOS NO ESTUDO}

Com base nos termos do debate sobre a participação de empresas em CGV, com destaque para aspectos como possibilidades dos países, percursos produtivos no âmbito das cadeias e, tendo-se em conta as exigências para upgrading, importância da inovação, examina-se a situação da Argentina, como indicado na introdução. Inicia-se pela formulação de algumas hipóteses visando nortear a observação da participação de economias de renda média em CGV, e depois se fala da fonte dos dados e da metodologia usada.

\subsection{HIPÓTESES SOBRE A INSERÇÃO DE EMPRESAS INDUSTRIAIS ARGENTINAS EM CGV E OS CORRESPONDENTES REFLEXOS}

H1: A inserção de uma economia de média renda em CGV implica manufaturas de baixa intensidade tecnológica (BT), média intensidade tecnológica (MBT/MAT) e alta intensidade tecnológica (AT), além de fornecimento de insumos. 
H2: A inserção de uma economia de renda média acontece em etapas intensivas em mão de obra, envolvendo processamento e montagem, sem processo de endogeneização tecnológica e com forte presença de provedores externos, o que repercute em perda de valor adicionado (VA) pela economia do país.

H3: Empresas com maior capacidade de absorção (CA) de informação conseguem explorar o conhecimento externo de forma mais eficiente, aumentando o seu desempenho inovativo e sua inserção em CGV.

H4: A colaboração indústria-universidade promove o desenvolvimento de inovações com elevado grau de complexidade, incluindo novos produtos e favorecendo uma participação em CGV caracterizada por maior desenvolvimento e complexidade em produtos e processos.

\subsection{FONTE DOS DADOS E METODOLOGIA}

Utilizou-se a base de dados referente à Encuesta Nacional de Dinámica de Empleo e Innovación (ENDEI), ${ }^{3}$ desenvolvida pelo Ministerio de Trabajo, Empleo y Seguridad Social (MTEySS) em parceria com o Ministerio de Ciencia, Tecnología e Innovación Productiva da Argentina. A pesquisa que originou essa base, abrangendo o período 2010-2012, cobriu 3.691 empresas com 10 ou mais trabalhadores, representando cerca de $24 \%$ da indústria de transformação argentina, que concentra $88 \%$ do emprego industrial formal registrado (ARGENTINA, 2015a).

Assume-se no estudo que as empresas mais fortemente inseridas em CGV são as que conseguem atingir mercados globais com seus produtos, embora se saiba que as exportações não representam, forçosamente, participação em CGV. Contribuíram para esse entendimento, assinale-se, os avanços logrados na construção de matrizes insumo-produto em escala global, permitindo análises sobre vínculos para frente e para trás dos diferentes países considerando-se a incidência de valor agregado no comércio. Estudos como o de Banga (2013) exemplificam as possibilidades analíticas assim surgidas, ampliando o escopo para abordagens sobre a distribuição dos ganhos decorrentes do envolvimento em CGV, das quais o estudo de Dedrick, Kraemer e Linden (2010) constitui uma útil ilustração.

\footnotetext{
Publicada em 2015, trata-se de uma pesquisa conjunta dos Ministérios de Ciência, Tecnologia e Inovação Produtiva, o de Trabalho, Emprego e Seguridade Social da Argentina, junto ao Banco Interamericano de Desenvolvimento (BID).
} 
Mais recentemente, Wang et al. (2017) disponibilizaram instrumento para decompor as atividades produtivas dos países conforme a destinação das mercadorias. Esta aparece como somente doméstica, como internacional sem envolver bens intermediários (no marco de um comércio "tradicional", conforme indicado), como caracterizada por vínculos em CGV, mas implicando atividades simples, ou como marcada por tais relações, porém envolvendo atividades complexas. A importância da contribuição é sinalizada desta maneira: "[a]plicando nossas ferramentas à mais atual base de dados insumo-produto entre países [...], mostramos que as CGV complexas foram a mais importante força motriz para a globalização, movimentando-se fortemente em paralelo com o crescimento do PIB global [...]" (WANG et al., 2017, p. 31, tradução nossa).

A posição, assumida neste estudo, de que as exportações indicam o grau de envolvimento em CGV decorre das restrições da base de dados utilizada. Com efeito, por exemplo, a base informa não sobre produtos, mas somente sobre setores. Assim, tem-se consciência de que o estudo apresenta limitações, sobretudo em face do que já se atingiu na mensuração do envolvimento de países em CGV, conforme apresentado na literatura internacional.

A manifestada posição sobre o significado da exportação levou à construção de cinco variáveis binárias dependentes, pelas quais as empresas declaram exportar (1) ou não exportar (0) para qualquer mercado externo, conforme mensurado pela variável "exporta", ou seguindo os seguintes recortes: exportações para o Mercosul e restantes dos países da América Latina - variável “exp_al”; exportações para a América do Norte - variável “exp_an”; exportações para a Europa - variável “exp_eu”; e exportações para Ásia, África e Oceania - conforme mensurado pela variável "exp_aao". Deve-se ressaltar que tal categorização da destinação das exportações teve por base as informações disponibilizadas na base de dados original, ao mesmo tempo em que se procurou manter um número mínimo de empresas por grupo. Para cada uma das variáveis dependentes, estimou-se um modelo Probit, ${ }^{4}$ conforme a equação (1), dando origem aos cinco modelos avaliados nesta pesquisa.

$$
\operatorname{Prob}\left(Y_{i} \mid X_{i}\right)=\phi\left(X^{T} \beta\right)
$$

Em (1), Prob denota a probabilidade; $Y_{i}$ representa a variável dependente, que para os modelos 1, 2, 3, 4 e 5, assume os valores das variáveis de exportação geral, exportações para a América Latina, América do Norte, Europa e Ásia, África e Oceania, respectivamente; $\phi$

\footnotetext{
4 Para uma explicação mais detalhada desse modelo, ver Greene e Hensher (2010).
} 
é a função de distribuição acumulada (FDP) de uma distribuição normal padrão; a matriz $X^{T}$ representa as variáveis explicativas agrupadas em variáveis relacionadas à complexidade tecnológica, à fonte dos provedores de insumos, à capacidade de absorção e inovação, ao desenvolvimento de atividades de $\mathrm{P} \& \mathrm{D}$ e à estrutura de capital da empresa. Os parâmetros $\beta$ são estimados por Máxima Verossimilhança.

A interpretação dos resultados deve observar que, com base nas características da empresa $i$, chega-se a um valor para $Y_{i}$ que identifica o tipo de vínculo com maior probabilidade de ocorrer em tal empresa. $\mathrm{Na}$ abordagem, o foco recai na significância, e o sinal dos parâmetros $\beta$ indica quais variáveis têm relação com o tipo de vínculo estabelecido, além de apontar se tal relação é positiva ou negativa. Todas as variáveis independentes foram selecionadas junto aos microdados da referida base de dados. Para uma melhor estimação do modelo, utilizam-se como controle as variáveis binárias relacionadas ao tamanho da empresa: pequena, média ou grande [tam_peq, tam_med, tam_gra]. O Quadro 1 a seguir apresenta as variáveis independentes e os fundamentos conceituais/analíticos cuja observação pretende-se lograr.

\section{Quadro 1 - Descrição das variáveis explicativas dos modelos estimados}

\begin{tabular}{|c|c|}
\hline Variável & Descrição \\
\hline \multicolumn{2}{|r|}{ Complexidade Tecnológica } \\
\hline $\begin{array}{l}\text { AT MAT BT } \\
\text { MBT }\end{array}$ & $\begin{array}{l}\text { São variáveis dicotômicas criadas com base no nível tecnológico dos setores industriais (são } 27 \text { os } \\
\text { setores computados). Entende-se que uma maior associação do setor tecnológico com a variável } \\
\text { desfecho exportação sinaliza a forma de inserção nas CGV e, consequentemente, o estágio } \\
\text { produtivo do país. De acordo com a literatura, espera-se que, quanto maior o nível tecnológico, } \\
\text { melhor é a inserção da economia em CGV. }\end{array}$ \\
\hline \multicolumn{2}{|r|}{ Provedores de Insumos } \\
\hline $\begin{array}{l}\text { imp_al, imp_an, } \\
\text { imp_eu, } \\
\text { imp-aao }\end{array}$ & $\begin{array}{l}\text { São variáveis que marcam a distribuição geográfica do provedor de insumos. O recorte dado na } \\
\text { presente análise trabalhou com quatro grupos regionais: Mercosul e América Latina, América do } \\
\text { Norte, Europa e Ásia, África e Oceania. Essa variável permite uma dupla interpretação. Por um lado, } \\
\text { entende-se que quanto mais volumosa é a importação de insumos, maior a inserção em CGV. Por } \\
\text { outro lado, com importaçães, a economia deixa de internalizar parcela significativa do VA, e isso seria } \\
\text { um indicativo de inserção da economia por meio dos estágios iniciais da trajetória produtiva. }\end{array}$ \\
\hline \multicolumn{2}{|r|}{ Capacidade de Absorção e Inovação } \\
\hline $\begin{array}{l}\text { prop_- } \\
\text { engenheiro }\end{array}$ & $\begin{array}{l}\text { Proporção média (entre } 2010 \text { a 2012) de profissionais engenheiros e das áreas de ciências naturais e } \\
\text { exatas dentro do quadro total de empregados. De acordo com a literatura apontada, entende-se que } \\
\text { uma maior parcela de mão de obra qualificada está associada a uma maior capacidade de absorção } \\
\text { da firma, potencializando a capacidade de upgrading do país. O sinal da associação seria, portanto, } \\
\text { um indicador da qualidade da inserção na CGV. }\end{array}$ \\
\hline fontes_ext & $\begin{array}{l}\text { Variável de contagem que indica o número de fontes externas de conhecimento que a firma utilizou } \\
\text { no período, entre as seguintes alternativas: i) firmas do mesmo grupo de controle; ii) provedores e/ } \\
\text { ou clientes; iii) competidores; iv) consultores; v) universidade pública e/ou privada; vi) instituições } \\
\text { públicas de C\&T; vii) internet e redes de informação; viii) câmaras de empresariais; ix) feiras, } \\
\text { exposições, conferências e congressos; e x) publicações técnicas, catálogos e revistas do setor. } \\
\text { Quanto maior o número de fontes de informação utilizadas, mais aberta é a empresa, maior tende a } \\
\text { ser sua capacidade de absorção e de alcance de upgrading. }\end{array}$ \\
\hline
\end{tabular}


Quadro 1 - Descrição das variáveis explicativas dos modelos estimados

\begin{tabular}{|c|c|}
\hline Variável & Descrição \\
\hline uni_inst & $\begin{array}{l}\text { Essa variável indica se a empresa estabeleceu vínculos de colaboração com universidades e/ou } \\
\text { instituições públicas de C\&T para desenvolver inovações. Conforme sugerido na literatura, essa } \\
\text { variável apontaria a inserção da empresa em CGV por meio de inovação radical, o que de maneira } \\
\text { indireta indicaria um ambiente mais propício ao upgrading de cadeia e funcional. }\end{array}$ \\
\hline consultores & $\begin{array}{l}\text { Variável que capta a criação de vínculos de colaboração da empresa com consultores. Na presente } \\
\text { amostra utilizada, observou-se uma forte associação dessa variável com inovações incrementais. } \\
\text { Nesse caso, o sinal da variável seria um indicativo da forma de participação em CGV, } \\
\text { relacionando-se com upgrading de produto e/ou de processo. }\end{array}$ \\
\hline inova & $\begin{array}{l}\text { Variável dicotômica que indica se a firma praticou alguma inovação no período, seja de produto, de } \\
\text { processo ou organizacional. É uma proxy para inovação que leva a upgrading, sendo esperada uma } \\
\text { relação positiva com as exportações. }\end{array}$ \\
\hline result_merc & $\begin{array}{l}\text { Variável dicotômica que indica se a inovação realizada resultou em ingresso em novos mercados. É } \\
\text { uma proxy para inovação, que propicia a entrada em novos mercados e em CGV, esperando-se uma } \\
\text { relação positiva com as exportações. }\end{array}$ \\
\hline \multicolumn{2}{|r|}{ Desenvolvimento de Atividades de P\&D } \\
\hline ln_inv & $\begin{array}{l}\text { Média dos anos } 2010 \text { a } 2012 \text { do logaritmo dos gastos com atividades de inovação. A variável procura } \\
\text { registrar esforços em inovação, além dos vinculados a P\&D, tais como treinamento, implementação } \\
\text { dos produtos, atividades internas de engenharia e aquisição externa de tecnologia. Admite-se que, } \\
\text { quanto maior esse esforço, maior é a capacidade das firmas para absorver conhecimento. }\end{array}$ \\
\hline \multicolumn{2}{|r|}{ Estrutura de Capital } \\
\hline cap_ext & $\begin{array}{l}\text { Essa variável indica se a empresa apresenta participação de capital internacional. A participação de } \\
\text { capital internacional seria um indicador da inserção em CGV e, portanto, espera-se uma associação } \\
\text { positiva com exportação. Contudo, sob o ponto de vista de governança das CGV, essa variável se associa } \\
\text { à presença de empresas subsidiárias de multinacionais, essas últimas vistas como líderes de CGV. }\end{array}$ \\
\hline \multicolumn{2}{|r|}{ Variáveis de Controle } \\
\hline $\begin{array}{l}\text { tam_peqtam_ } \\
\text { medtam_gra }\end{array}$ & $\begin{array}{l}\text { Variáveis com relação ao tamanho da empresa: pequena, média ou grande, todas binárias, } \\
\text { conforme classificação adotada na citada base de dados da ENDEI. }\end{array}$ \\
\hline
\end{tabular}

Fonte: Elaboração própria.

\section{A INDÚSTRIA ARGENTINA E AS CGV: RESULTADOS DA EXPLORAÇÃO DA BASE DE DADOS}

\subsection{CARACTERIZAÇÃO DA INSERÇÃO EXTERNA ARGENTINA}

Como outros países em desenvolvimento, a inserção argentina no comércio mundial se associa, tradicionalmente, a commodities agrícolas e minerais. Em 2016, 54,5\% das exportações argentinas tinham origem no setor de recursos naturais, e só 10 produtos respondiam por $50 \%$ das exportações totais. Observe-se que uma maior diversificação das exportações pode atuar como força que reduz a volatilidade externa. Especificamente, a diversificação pode diminuir a extensão dos efeitos negativos de aumentos e diminuições dos termos de troca (HUERTAS e IRARRÁZAVAL, 2019). 
Como indicado na Tabela 1, a atividade exportadora das firmas argentinas é caracterizada pela heterogeneidade setorial. Há dinamismo exportador nas indústrias farmacêutica, química e petroquímica e de maquinaria e equipamentos, além dos setores que são tradicionais nas vendas externas argentinas, como alimentos. Associando o dinamismo exportador à participação em CGV, nota-se que tal inserção se dá preponderantemente em setores de alta tecnologia (AT) e média alta tecnologia (MAT), aparentemente confirmando o que se assinalou anteriormente sobre o segundo estágio das cadeias.

Tabela 1 - Distribuição das empresas argentinas por setor industrial, 2012

\begin{tabular}{|c|c|c|c|c|}
\hline Setor da indústria & $\begin{array}{c}\text { Firmas não } \\
\text { exportadoras }\end{array}$ & $\begin{array}{c}\text { Firmas } \\
\text { exportadoras }\end{array}$ & Total & $\begin{array}{c}\text { Firmas } \\
\text { exportadoras }\end{array}$ \\
\hline Máquinas-ferramentas em geral (MAT) & 39 & 85 & 124 & $69 \%$ \\
\hline Farmacêuticas (AT) & 51 & 85 & 136 & $63 \%$ \\
\hline Produtos químicos (MAT) & 69 & 112 & 181 & $62 \%$ \\
\hline Vinhos e outras bebidas fermentadas (BT) & 40 & 61 & 101 & $60 \%$ \\
\hline Outros & 37 & 49 & 86 & $57 \%$ \\
\hline Instrumentos médicos (AT) & 34 & 45 & 79 & $57 \%$ \\
\hline Maquinaria agropecuária e florestal (MAT) & 33 & 43 & 76 & $57 \%$ \\
\hline Máquinas e equipamentos (MAT) & 54 & 67 & 121 & $55 \%$ \\
\hline Produtos de borracha e plástico (MBT) & 97 & 95 & 192 & $49 \%$ \\
\hline Autopeças (MAT) & 70 & 64 & 134 & $48 \%$ \\
\hline Material elétrico, rádio, televisão (AT) & 77 & 58 & 135 & $43 \%$ \\
\hline Eletrodomésticos (MAT) & 49 & 32 & 81 & $40 \%$ \\
\hline Outros produtos de metal (MBT) & 142 & 86 & 228 & $38 \%$ \\
\hline Produtos têxteis (BT) & 126 & 72 & 198 & $36 \%$ \\
\hline Carrocerias, reboques e semi-reboques (MBT) & 24 & 13 & 37 & $35 \%$ \\
\hline Outros equipamentos de transporte (MAT) & 50 & 24 & 74 & $32 \%$ \\
\hline Metais comuns (MBT) & 88 & 41 & 129 & $32 \%$ \\
\hline Alimentos (BT) & 233 & 103 & 336 & $31 \%$ \\
\hline Frigoríficos (BT) & 124 & 51 & 175 & $29 \%$ \\
\hline Couro (BT) & 96 & 39 & 135 & $29 \%$ \\
\hline Edição (BT) & 98 & 38 & 136 & $28 \%$ \\
\hline Papel (BT) & 99 & 36 & 135 & $27 \%$ \\
\hline Móveis (BT) & 100 & 33 & 133 & $25 \%$ \\
\hline Outros minerais não metálicos (MBT) & 99 & 31 & 130 & $24 \%$ \\
\hline Produtos lácteos (BT) & 96 & 26 & 122 & $21 \%$ \\
\hline Confecções (BT) & 117 & 29 & 146 & $20 \%$ \\
\hline Madeira (BT) & 115 & 16 & 131 & $12 \%$ \\
\hline Total & 2.257 & 1.434 & 3.691 & $39 \%$ \\
\hline
\end{tabular}

Fonte: Elaboração própria com base em ENDEI (ARGENTINA, 2015a). 
Na Tabela 2 observa-se que quase $40 \%$ das firmas declararam ter atingido mercados internacionais. Dessas, 37\% tiveram presença no conjunto Mercosul e América Latina, 8,6\% no grupo América do Norte e Canadá, 10,5\% na Europa e 9,6\% no recorte Ásia, África e Oceania, observando-se, portanto, um forte caráter (macro)regional nessas vendas externas. Ao mesmo tempo, tais empresas também utilizam insumos oriundos de outras regiões mundiais, na proporção de $60 \%$ do conjunto estudado. A observação da distribuição espacial das origens dos provedores permite constatar uma maior diversificação, comparativamente aos destinos das exportações. Os provedores de Mercosul e América Latina representam 24,8\%, os de América do Norte e Canadá, 16,2\%, os da Europa, 22,7\%, e os de Ásia, África e Oceania, 23,1\%.

Tabela 2 - Distribuição das variáveis dicotômicas

\begin{tabular}{|c|c|c|c|c|}
\hline Variável & Valor & Frequência & Percentual & $\begin{array}{l}\text { Percentual } \\
\text { Acumulado }\end{array}$ \\
\hline \multirow{2}{*}{ exporta } & 0 & 2.257 & 61,2 & 61,2 \\
\hline & 1 & 1.434 & 38,9 & 100,0 \\
\hline \multirow{2}{*}{$A T$} & 0 & 3.341 & 90,5 & 90,5 \\
\hline & 1 & 350 & 9,5 & 100,0 \\
\hline \multirow{2}{*}{ MAT } & 0 & 2.900 & 78,6 & 78,6 \\
\hline & 1 & 791 & 21,4 & 100,0 \\
\hline \multirow{2}{*}{$M B T$} & 0 & 2.975 & 80,6 & 80,6 \\
\hline & 1 & 716 & 19,4 & 100,0 \\
\hline \multirow{2}{*}{$B T$} & 0 & 1.943 & 52,6 & 44,8 \\
\hline & 1 & 1.748 & 47,6 & 100,0 \\
\hline \multirow{2}{*}{ importa } & 0 & 2.176 & 59,0 & 59,0 \\
\hline & 1 & 1.515 & 41,0 & 100,0 \\
\hline \multirow{2}{*}{ inova } & 0 & 1.256 & 34,0 & 34,0 \\
\hline & 1 & 2.435 & 66,0 & 100,0 \\
\hline \multirow{2}{*}{ result_merc } & 0 & 2.706 & 73,3 & 73,3 \\
\hline & 1 & 985 & 26,7 & 100,0 \\
\hline \multirow{2}{*}{ uni_inst } & 0 & 2.627 & 71,2 & 71,2 \\
\hline & 1 & 1.064 & 28,8 & 100,0 \\
\hline \multirow{2}{*}{ consultores } & 0 & 2.341 & 63,4 & 63,4 \\
\hline & 1 & 1.350 & 36,6 & 100,0 \\
\hline \multirow{2}{*}{ parte_grupo } & 0 & 3.236 & 87,7 & 87,7 \\
\hline & 1 & 455 & 12,3 & 100,0 \\
\hline \multirow{2}{*}{ cap_ext } & 0 & 3.354 & 90,9 & 90,9 \\
\hline & 1 & 337 & 9,1 & 100,0 \\
\hline \multirow{3}{*}{ tamanho } & peq & 1.569 & 42,5 & 42,5 \\
\hline & med & 1.352 & 36,6 & 79,1 \\
\hline & gra & 770 & 20,9 & 100,0 \\
\hline
\end{tabular}

Fonte: Elaboração própria com base em ENDEI (ARGENTINA, 2015a). 
Em relação ao nível regional, as províncias argentinas permitem observar diferentes níveis de complexidade nas suas respectivas atividades. Na província de Buenos Aires e nas da região Centro (Córdoba, Santa Fe, Entre Ríos), ocorre uma maior sofisticação relativa na produção e exportação, comparativamente às regiões do norte e do sul (HUERTAS e IRARRÁZAVAL, 2019).

As firmas inseridas em CGV precisam construir capacidades especificas de produção e se atualizar constantemente para permanecer dentro desse tipo de arranjo. As variáveis relacionadas à inovação mostram que as firmas da base de dados procuram inovar, tendo $2 / 3$ dos casos registrado algum tipo de inovação no período. Já o acesso a novos mercados, como decorrência do processo de inovação, caracteriza $26,7 \%$ das empresas. Outro aspecto é que, na amostra de 3.691 empresas, 28,8\% possuíam vínculos com universidades e instituições públicas de C\&T, e 36,6\% com empresas de serviços de negócios intensivos em conhecimento (consultores). Cabe igualmente salientar que a maioria das empresas tem porte pequeno e médio, que apenas $9 \%$ contam com capital internacional e que $12,3 \%$ mantiveram interações com outras empresas do grupo ou com sua matriz para realizar inovações.

As empresas pesquisadas gastaram com inovação, em média, uma cifra próxima a US\$ 413 mil por ano (Tabela 3). Essa variável apresenta grande dispersão, refletindo a própria dispersão do tamanho das empresas argentinas, em linha com o resultado encontrado por Tether e Tajar (2008). No estudo desses autores, o valor médio do gasto com inovação foi de $£ 1,4$ milhão, enquanto a mediana foi de $£ 38.500$, indicando a preponderância de micro e pequenas firmas na amostra da respectiva pesquisa sobre o Reino Unido.

Tabela 3 - Gastos com inovação

\begin{tabular}{lccccc}
\hline Variável & Observações & $\begin{array}{c}\text { Média } \\
(\text { US\$) }\end{array}$ & $\begin{array}{c}\text { Desvio Padrão } \\
\text { (US\$) }\end{array}$ & $\begin{array}{c}\text { Min. } \\
\text { (US\$) }\end{array}$ & $\begin{array}{c}\text { Max. } \\
\text { (US\$) }\end{array}$ \\
\hline inno_total2010 & 3691 & 337.526 & 2.338 .876 & 0 & 46.197 .675 \\
inno_total2011 & 3691 & 459.542 & 3.600 .886 & 0 & 72.504 .319 \\
inno_total2012 & 3691 & 442.543 & 2.865 .393 & 0 & 60.393 .661 \\
gasto_innv (2010-2012) & 3691 & 413.204 & 2.935 .051 & 0 & 59.698 .551 \\
\hline
\end{tabular}

Nota: (*) Dados de câmbio em Ipeadata (IFS/FMI). Dados em Pesos correntes transformados em dólares pela taxa câmbio Peso/US\$, média do período; Peso/US $\$(2010)=3,8963$, Peso/US\$(2011) $=4,1101$, Peso/US $\$(2012)=4,5369$ Fonte: Elaboração própria com base em ENDEI (ARGENTINA, 2015a).

A Tabela A1 (Apêndice) informa que quase 40\% das firmas não utilizaram fontes externas de conhecimentos no período. Trata-se, vale ressaltar, de uma proporção bastante elevada, no cotejo com resultados de pesquisas semelhantes: em Tether e Tajar (2008), por exemplo, o correspondente nível é de aproximadamente 3\%. 
De outra parte, a proporção de funcionários relacionados às engenharias ou com formação nas áreas de ciências naturais e exatas, apresenta uma média de $22 \%$ nos três anos observados (Tabela A2, no Apêndice). A incidência é alta, se comparada ao resultado obtido por Tether e Tajar (2008), que detectaram uma proporção de $8 \%$ para ciências e engenharias e de $9 \%$ para outras formações universitárias.

\subsection{RESULTADOS DOS MODELOS ESTIMADOS}

Foram igualmente estimados cinco modelos Probit, relacionando a inserção das empresas argentinas em CGV com suas características chaves, definidas de acordo com a literatura utilizada para embasar o estudo. Os resultados dessas estimações encontram-se na Tabela 4.

A abordagem das hipóteses de pesquisa apresentadas em 3.1 desenvolve-se como segue.

H1: A inserção de uma economia de média renda em CGV implica manufaturas de baixa intensidade tecnológica (BT), média intensidade tecnológica (MBT/MAT) e alta intensidade tecnológica (AT), além de fornecimento de insumos ${ }^{5}$.

Conforme a adaptação da "curva sorriso" proposta em Corrêa, Pinto e Castilho (2017), a inserção de uma economia de renda média como a Argentina em CGV implicaria manufaturas de baixa intensidade tecnológica (BT), média intensidade tecnológica (MBT/MAT) e alta intensidade tecnológica (AT), e também fornecimento de insumos. Pelas informações do Quadro 1, com 27 setores relacionados, sete registram mais de $50 \%$ das firmas com clientes no exterior. Desses, seis são manufatureiros MAT/AT.

Na modelagem econométrica da Tabela 4, os coeficientes estimados indicam que pertencer a um setor de MAT aumenta a chance de inserção internacional da empresa mediante exportações. Os coeficientes relacionados aos setores de AT não se mostraram significativos nos modelos referentes às exportações globais (exporta), às exportações para a América Latina (exp_al) e àquelas para a América do Norte (exp_ an), ao contrário do verificado quando se tratou de Europa (exp_eu) e de Ásia, África e Oceania (exp_aao).

\footnotetext{
Cabe destacar, como mencionado em Corrêa, Pinto e Castilho (2017) que a análise ideal da inserção dentro das CGV deveria ser realizada a partir das tarefas executadas pelos diferentes países. Nesse caso, seria necessário contar com informação detalhada de comercio intraindústria. A base de dados disponível não permite essa possibilidade.
} 
Tabela 4 - Resultados dos modelos econométricos

\begin{tabular}{|c|c|c|c|c|c|}
\hline Variável & $\begin{array}{l}\text { Modelo } 1 \\
\text { (exporta) }\end{array}$ & $\begin{array}{c}\text { Modelo } 2 \\
\text { (exp_al) }\end{array}$ & $\begin{array}{l}\text { Modelo } 3 \\
\text { (exp_an) }\end{array}$ & $\begin{array}{c}\text { Modelo } 4 \\
\text { (exp_eu) }\end{array}$ & $\begin{array}{l}\text { Modelo } 5 \\
\text { (exp_aao) }\end{array}$ \\
\hline \multicolumn{6}{|c|}{ Complexidade Tecnológica } \\
\hline \multirow{2}{*}{ AT } & 0.139 & 0.117 & 0.0618 & $0.312^{* *}$ & $0.659^{* * *}$ \\
\hline & $(0.111)$ & $(0.110)$ & $(0.153)$ & $(0.138)$ & $(0.142)$ \\
\hline \multirow{2}{*}{ MAT } & $0.295^{\star * *}$ & $0.308^{\star * *}$ & $0.297^{\star *}$ & $0.243^{* *}$ & $0.345^{\star * *}$ \\
\hline & $(0.0876)$ & $(0.0874)$ & $(0.118)$ & $(0.112)$ & $(0.123)$ \\
\hline \multirow{2}{*}{ BT } & -0.121 & $-0.176^{* *}$ & $0.532^{\star * *}$ & $0.420^{* * *}$ & $0.565^{\star * *}$ \\
\hline & $(0.0748)$ & $(0.0751)$ & $(0.109)$ & $(0.103)$ & $(0.114)$ \\
\hline \multicolumn{6}{|c|}{ Provedores de Insumos } \\
\hline \multirow{2}{*}{ imp_al } & $0.437^{* * *}$ & $0.461^{* * *}$ & $0.250^{* * *}$ & $0.183^{* *}$ & $0.222^{* *}$ \\
\hline & $(0.0729)$ & $(0.0725)$ & $(0.0921)$ & $(0.0874)$ & $(0.0890)$ \\
\hline \multirow{2}{*}{ imp_an } & $0.182^{\star *}$ & $0.186^{\star *}$ & $0.248^{\star *}$ & $0.278^{* * *}$ & $0.184^{*}$ \\
\hline & $(0.0899)$ & $(0.0891)$ & $(0.0972)$ & $(0.0950)$ & $(0.0970)$ \\
\hline \multirow{2}{*}{ imp_eu } & $0.440^{* * *}$ & $0.372^{* * *}$ & $0.499^{* * *}$ & $0.463^{* * *}$ & $0.452^{* * *}$ \\
\hline & $(0.0766)$ & $(0.0762)$ & $(0.0924)$ & $(0.0895)$ & $(0.0908)$ \\
\hline \multirow{2}{*}{ imp_aao } & $0.299^{* * *}$ & $0.307^{\star * *}$ & -0.0677 & -0.0650 & -0.132 \\
\hline & $(0.0740)$ & $(0.0738)$ & $(0.0951)$ & $(0.0894)$ & $(0.0893)$ \\
\hline \multicolumn{6}{|c|}{ Capacidade de Absorção e Inovação } \\
\hline \multirow{2}{*}{$\begin{array}{l}\text { prop_ } \\
\text { engenheiro }\end{array}$} & $0.00256^{\star * *}$ & $0.00301^{* * *}$ & $0.00331^{* * *}$ & 0.000979 & $0.00196^{*}$ \\
\hline & $(0.000932)$ & $(0.000930)$ & $(0.00115)$ & $(0.00112)$ & $(0.00117)$ \\
\hline \multicolumn{6}{|l|}{ o.inova } \\
\hline \multirow{2}{*}{ result_merc } & $0.242^{* * *}$ & $0.240^{* * *}$ & $0.157^{\star *}$ & $0.272^{* * *}$ & $0.257^{* * *}$ \\
\hline & $(0.0589)$ & $(0.0591)$ & $(0.0769)$ & $(0.0722)$ & $(0.0748)$ \\
\hline \multirow{2}{*}{ uni_inst } & $0.266^{* * *}$ & $0.273^{\star * *}$ & $0.143^{*}$ & $0.185^{\star *}$ & $0.196^{\star *}$ \\
\hline & $(0.0667)$ & $(0.0668)$ & $(0.0867)$ & $(0.0817)$ & $(0.0822)$ \\
\hline \multirow{2}{*}{ consultores } & 0.0251 & 0.0270 & 0.0572 & -0.0164 & 0.0256 \\
\hline & $(0.0627)$ & $(0.0631)$ & $(0.0823)$ & $(0.0775)$ & $(0.0789)$ \\
\hline \multirow{2}{*}{ fontes_ext } & $0.0298^{* *}$ & $0.0374^{* * *}$ & 0.00725 & 0.0243 & 0.0195 \\
\hline & $(0.0133)$ & $(0.0134)$ & $(0.0168)$ & $(0.0163)$ & $(0.0172)$ \\
\hline \multicolumn{6}{|c|}{ Desenvolvimento de Atividades de P\&D } \\
\hline \multirow{2}{*}{ ln_inv } & 0.0133 & 0.00272 & 0.0239 & -0.0120 & $0.0552^{\star *}$ \\
\hline & $(0.0195)$ & $(0.0195)$ & $(0.0250)$ & $(0.0235)$ & $(0.0256)$ \\
\hline \multicolumn{6}{|c|}{ Estrutura de Capital } \\
\hline \multirow{2}{*}{ cap_ext } & $0.190^{*}$ & $0.184^{\star}$ & $0.306^{\star * *}$ & $0.389^{* * *}$ & 0.0807 \\
\hline & $(0.107)$ & $(0.106)$ & $(0.109)$ & $(0.105)$ & $(0.110)$ \\
\hline
\end{tabular}


Tabela 4 - Resultados dos modelos econométricos

\begin{tabular}{lccccc}
\hline Variável & $\begin{array}{c}\text { Modelo 1 } \\
\text { (exporta) }\end{array}$ & $\begin{array}{c}\text { Modelo 2 } \\
\text { (exp_al) }\end{array}$ & $\begin{array}{c}\text { Modelo 3 } \\
\text { (exp_an) }\end{array}$ & $\begin{array}{c}\text { Modelo 4 } \\
\text { (exp_eu) }\end{array}$ & $\begin{array}{c}\text { Modelo 5 } \\
\text { (exp_aao) }\end{array}$ \\
\hline \multicolumn{5}{c}{ Variáveis de Controle } \\
\hline \multirow{2}{*}{ tam_peq } & $-0.283^{* * *}$ & $-0.308^{* * *}$ & -0.0161 & $-0.168^{*}$ & $-0.244^{* *}$ \\
& $(0.0678)$ & $(0.0685)$ & $(0.0994)$ & $(0.0923)$ & $(0.101)$ \\
tam_gra & $0.183^{* *}$ & $0.177^{* *}$ & 0.148 & $0.248^{* *}$ & $0.301^{* * *}$ \\
& $(0.0834)$ & $(0.0833)$ & $(0.102)$ & $(0.0963)$ & $(0.0988)$ \\
Constant & $-0.958^{* * *}$ & $-0.896^{* * *}$ & $-2.573^{* * *}$ & $-1.933^{* * *}$ & $-2.958^{* * *}$ \\
Pseudo R2 & $(0.246)$ & $(0.245)$ & $(0.333)$ & $(0.307)$ & $(0.342)$ \\
Wald Chi2 & 0.2051 & 0.2109 & 0.1521 & 0.1474 & 0.1788 \\
AIC & 513.51 & 535.24 & 241.21 & 274.62 & 278.14 \\
Observations & 2.634 .703 & 2.608 .448 & 1.541 .572 & 1.656 .569 & 1513.66 \\
\hline
\end{tabular}

Robust standard errors in parentheses

*** $\mathrm{p}<0.01,{ }^{* *} \mathrm{p}<0.05,{ }^{*} \mathrm{p}<0.1$

Fonte: Elaboração própria com base em ENDEI (ARGENTINA, 2015a).

Para a América Latina, o coeficiente de BT foi negativo, sugerindo que pertencer a um setor de baixa tecnologia diminui a probabilidade de exportar para tal região. Entretanto, esse resultado deve ser visto com cautela, pois, dada a alta concentração regional das exportações argentinas, pode haver algum tipo de competição entre as pautas de exportação dos setores de BT nos países do subcontinente. Resultado diverso é encontrado, para os coeficientes dos setores de BT, quando se trata de vendas para América do Norte, Europa e o conjunto de Ásia, África e Oceania: todos são positivos e significativos. De todo modo, não carece de lógica considerar que os pobres resultados em exportações de setores de BT para a América Latina podem funcionar como estímulo, em algum grau, para que essas empresas procurem transitar para setores mais complexos tecnologicamente.

Acredita-se, assim, que o modo de participação das empresas argentinas em CGV é representativo do padrão exibido por países de renda média presentes no segundo estágio da "curva sorriso", na adaptação proposta em Corrêa, Pinto e Castilho (2017). A inserção desses países ocorre em cadeias de maior complexidade tecnológica, mas em etapas caracterizadas por menor VA.

H2: A inserção de uma economia de renda média acontece em etapas intensivas em mão de obra, envolvendo processamento e montagem, sem processo de endogeneização tecnológica e com forte presença de provedores externos, o que repercute em perda de valor adicionado (VA) pela economia do país. 
Se a América Latina prepondera como destino das exportações no tocante à participação das empresas argentinas em CGV, o mesmo não se pode falar com respeito à inserção mediante importações. Nessas, a distribuição geográfica das origens dos fluxos mostra-se mais equilibrada, como comentado na seção 4.1 .

Os coeficientes das regressões econométricas indicam que as importações de países da América Latina (imp_al), da América do Norte (imp_an) e da Europa (imp_ eu) ampliam a probabilidade de exportar para todas as outras regiões. Curiosamente, as importações do bloco Ásia, África e Oceania (imp_aao) aumentam a probabilidade das exportações de uma maneira geral e para os países da América Latina, não sendo, porém, significativas para as exportações às demais regiões. Ou seja, inputs produtivos da variável imp_aao, transformados por firmas Argentinas, parecem estar inseridos em cadeia de valor voltada às exportações regionais.

Esses resultados autorizam algumas observações. Primeiro, sugerem o prevalecente caráter de montagem e processamento nas atividades protagonizadas pelas empresas argentinas, sob o signo de uma pequena endogeneização tecnológica. Segundo, ainda que de maneira preliminar e carente de análises complementares sobre a pauta de produtos importados por regiões, esta análise baseada em microdados permite algumas sinalizações sobre as posições e os direcionamentos das CGV.

H3: Empresas com maior capacidade de absorção (CA) de informação conseguem explorar o conhecimento externo de forma mais eficiente, aumentando o seu desempenho inovativo e sua inserção em CGV.

A análise das estatísticas descritivas, conforme a Tabela 2, informa que 2/3 das firmas declararam inovar e aproximadamente $27 \%$ tiveram alguma inovação capaz de resultar em presença em algum novo mercado. Contudo, pela Tabela A1 (no Apêndice) observa-se que quase $40 \%$ não buscaram sequer uma única fonte externa de conhecimento especializado, um assunto do tipo explorado na abordagem de Chesbrough (2003) sobre "inovação aberta", como tangenciado anteriormente. Cotejando com as estimativas obtidas para a variável fontes_ext, observa-se que elas foram significativas e positivas para as exportações em geral e para os países das América Latina. Nos demais modelos, a variável também foi positiva, porém não se mostrou significativa.

Tendo em vista a concentração das exportações argentinas, percebe-se que a busca por fontes externas no processo de inovação é relevante para as exportações regionais do país. Tais resultados estariam a reforçar o que se abordou com respeito à primeira hipótese, de que, em algum grau, o comércio no âmbito do bloco regional possa estar colaborando para o processo de marco da inserção em CGV.

A Tabela 4 mostra que a variável inova foi omitida por colinearidade. Contudo, a variável rest_merc, que mensura as inovações que resultam em novos mercados, foi 
positiva e significativa em todos os modelos, o que sugere, como um resultado bastante forte, haver uma associação entre inovação e potencial exportador e, consequentemente, inserção das firmas nas CGV. Os coeficientes da variável prop_engenheiro, que considera a parcela de profissionais engenheiros e com formação em ciências naturais e exatas representando uma proxy para CA -, foram positivos e significativos para todos os modelos, excetuado o relativo à Europa (expo_eu). Depreende-se, assim, que tal variável indica que, de fato, uma maior CA vai de par com uma maior inserção em CGV.

Por outro lado, o gasto com inovação não se mostrou significativo. Nesse caso, deve-se levar em conta o contexto do SNI argentino, em que é forte a preponderância dos investimentos públicos em inovação. De acordo com a publicação Indicadores de Ciencia y Tecnología Argentina, em 2013 cerca de 75\% dos gastos com inovação foram realizados pelo setor público, enquanto empresas públicas e privadas responderam por 22\% desses investimentos (ARGENTINA, 2015b).

H4: A colaboração indústria-universidade promove o desenvolvimento de inovações com elevado grau de complexidade, incluindo novos produtos e favorecendo uma participação em CGV caracterizada por maior desenvolvimento e complexidade em produtos e processos.

Os coeficientes da regressão parecem condizentes com essa hipótese. Em todos os casos, ter vínculo com universidade ou instituição de C\&T aumenta a probabilidade de a firma exportar e inserir-se em CGV. De outra parte, os coeficientes relacionados ao uso de consultores privados não representaram ampliação da probabilidade de uma maior inserção das firmas em CGV.

Por fim, deve-se fazer menção aos coeficientes obtidos com a variável cap_ext, os quais foram positivos e significativos a 90\% para as exportações em geral e aos países da América do Sul. Para os modelos 3 e 4, que representam as exportações para América do Norte e Europa, ter capital externo na composição da firma aumenta o potencial exportador com nível de significância de 99\%. Por outro lado, para as exportações para a Ásia, África e Oceania, ter capital externo na composição não tem significância estatística para o potencial exportador.

Esses resultados são interessantes e coerentes com o processo de industrialização de países como Argentina, Brasil e México, em cujos processos se verificam uma forte presença de empresas multinacionais norte-americanas e europeias. Além disso, tais resultados, em conjunto com os obtidos em relação aos coeficientes da variável de importação de Ásia, África e Oceania (imp_aao), sinalizam que as cadeias que envolvem países do oriente parecem possuir e executar estratégias distintas, na comparação com aquelas marcadamente ocidentais. 


\section{CONSIDERAÇÕES FINAIS}

O aumento da presença de CGV, como espécie de configuração proeminente na produção e no comércio internacional nas últimas décadas, tornou a participação dos diferentes tipos de países um importante tema de investigação acadêmica, além de estimular a formulação e a execução de políticas a respeito. Segundo a literatura, países de renda média geralmente têm lugar nessas cadeias como fabricantes e exportadores de produtos representativos de distintas intensidades tecnológicas, porém relacionados a etapas produtivas em que são comparativamente maiores a presença do uso de mão de obra e a incidência de processamento e montagem final, em contexto de fraca endogeneização tecnológica.

Contudo, esse modo de envolvimento pode acenar para esses países com a possibilidade de transição rumo a etapas caracterizadas por maior valor agregado (VA), em upgrading, no âmbito das CGV, que, de uma forma ampla, costuma ter na dinâmica de inovação um vetor fundamental. Assim, principalmente no que concerne aos países de renda média, têm destaque no debate sobre CGV assuntos relacionados ao upgrading industrial e, por extensão, às condições que subjazem à sua possibilidade e ocorrência.

$\mathrm{O}$ artigo debruçou-se sobre esse tipo de problema examinando a situação de quase 3.700 empresas industriais argentinas, de diferentes setores e tamanhos, conforme possibilitado por uma base de dados construída em escala ministerial naquele país para os anos de 2010 a 1012. O manuseio desses dados, que incluiu a estimação de modelos Probit, corroboraram para a Argentina as postulações trazidas na literatura sobre o perfil do envolvimento de economias de renda média nas amplas estruturas produtivas e comerciais correspondentes às CGV.

Há que ter em mente que a referida base de dados não possibilita abordagens mais sofisticadas, como as que, trabalhando com informações sobre produtos, exploram o comércio em valor agregado ou diferenciam os destinos das produções nacionais, inclusive tipificando e distinguindo as CGV simples das CGV complexas. Na subseção

\section{2 foram tecidas algumas breves considerações sobre essas abordagens.}

Seja como for, e dentro dos limites impostos pela base de dados, notou-se entre as firmas argentinas algum dinamismo exportador em setores de alta e média/alta tecnologia, mas prevalecendo nas suas exportações, ao que parece, o caráter de montagem e processamento, com endogeneização tecnológica limitada. Essas vendas, como assinalado, apresentam elevada concentração em mercados da América Latina. De outra parte, considerável número dessas empresas declarou realizar inovações, com resultados comerciais importantes. Todavia, muitas não utilizavam fontes externas de obtenção de informações e conhecimento, uma questão central na problemática da cha- 
mada “inovação aberta”, como se falou. De todo modo, é comparativamente grande a proporção de engenheiros e de outros profissionais com formação em ciências naturais e exatas no corpo de assalariados dessas firmas, o que pode ser considerado promissor com vistas ao upgrading.

Nesse contexto, uma questão central - para firmas argentinas ou de outros países de renda média que registram envolvimento em CGV - diz certamente respeito, entre vários aspectos, a como intensificar e acelerar o processo de endogeneização tecnológica, para evitar o aprisionamento na armadilha da renda média, conforme abordado no corpo do artigo. Lograr sucesso nessa direção haveria de representar possibilidades concretas de avanços decisivos em upgrading, isto é, chances efetivas de migração para etapas associadas a patamares mais altos de VA nas estruturas das CGV. Nesse sentido, o presente artigo procurou trazer novos elementos ao debate sobre a participação de países latino-americanos em CGV, evidenciando características intrínsecas às firmas aptas a favorecer um maior dinamismo exportador com maiores níveis de VA.

O terreno a laborar, na experiência argentina e em outras semelhantes, não é outro senão, com destaque, o das políticas de apoio e fomento. Porém, tais políticas teriam que ser, de fato, concebidas tendo-se em vista a problemática específica da participação em CGV. Em que medida a Argentina e, entre outros países, também o Brasil estariam de fato procurando idealizar instrumentos de ação com tal perfil, que em vários sentidos parece exigir diferenciação do que se fez tradicionalmente nessas economias?

\section{REFERÊNCIAS}

ARGENTINA. ENDEI -Encuesta Nacional de Empleo e Innovación: documento de difusión. Buenos Aires: Ministerio de Ciencia, Tecnología e Innovación Productiva, 2015a. Disponível em: http://indicadorescti.mincyt.gob.ar. Acesso em: 13 nov. 2018.

ARGENTINA. Indicadores de Ciencia y Tecnología Argentina. Buenos Aires: Ministerio de Ciencia, Tecnología e Innovación Productiva, 2015b, p. 39-40.

ASHEIM, B.; GERTLER, M., The geography of innovation. In: FAGERBER, J.; MOWERY, D.; NELSON, R. (Eds.) The Oxford Handbook of Innovation. Oxford: Oxford University Press, 2005, p. 291-317.

BALDWIN, R. Trade and industrialisation after globalisation's 2nd unbundling: how building and joining a supply chain are different and why it matters. NBER Working Paper, n. 17716, Dec. 2011.

BALDWIN, R Global supply chains: why they emerged, why they matter, and where they are going. CEPR Discussion Papers, n. 9103, 2012.

BANGA, R. Measuring value in global value chains. UNCTAD Background Paper, n. RVC-8, May 2013. 
BELDERBOS, R. et al. Heterogeneity in R\&D co-operation strategies. International Journal of Industrial Organization, v. 22, p. 1237-63, 2004.

BHAGWATI, J.; DEHEJIA, V. Freer trade and wages of the unskilled: is Marx striking again? American Enterprise Institute Discussion Paper, n. 672, 1993.

BSTIELER, L.; HEMMERT, M.; BARCZAK, G. Trust formation in university-industry collaborations in the US biotechnology industry: IP policies, shared governance, and champions. Journal of Product Innovation Management, v. 32, n. 1, p. 111-21, 2015.

CARLSSON, B. (Ed.). Technological systems and industrial dynamics. Boston/Dordrecht/ London: Kluwer Academic Publishers, 1997.

CHESBROUGH, H. W. Open innovation: the new imperative for creating and profiting from technology. Boston: Harvard Business School Press, 2003.

COHEN, W. M.; LEVINTHAL, D. A. Absorptive capacity: a new perspective on learning and innovation. Administrative Science Quarterly, v. 35, p. 128-152, 1990.

COOMBS, R.; HARVEY, M.; TETHER, B.S. Analysing distributed processes of provision and innovation. Industrial and Corporate Change, v. 12, n. 6, p. 1125-1155, 2003.

CORRÊA, L. M.; PINTO, E. C.; CASTILHO, M. Trajetórias dos países nas cadeias globais de valor: padrões de atuação, estágios produtivos e mudança estrutural. Texto para Discussão, IE-UFRJ, n. 7, 2017.

DEDRICK, J.; KRAEMER, K. L.; LINDEN, L. Who Profits from Innovation in Global Value Chains? A Study of the iPod and notebook PCs. Industrial and Corporate Change, v. 19, n. 1, p. 81-116, Feb. 2010.

DOLLAR, D. Executive Summary. In: WORLD TRADE ORGANIZATION. Global value chain development report 2019: technological innovation, supply chain trade, and workers in globalized world. Geneva: WTO, 2019, p. 1-7.

EBERS, M.; MAURER, I. Connections count: how relational embeddedness and relational empowerment foster absorptive capacity. Research Policy, v. 43, p. 318 -332, 2014.

EDQUIST, C. (Ed.) Systems of innovation: technologies, institutions and organizations. London: Pinter, 1997.

EDQUIST, C. Systems of innovation: perspectives and challenges. In: FAGERBERG, J.; MOWERY, D.; NELSON, R. (Eds.) The Oxford Handbook of Innovation. Oxford: Oxford University Press, 2005, p. 181-208.

EICHENGREEN, B. Escaping the middle income trap. In: THE FEDERAL RESERVE BANK OF KANSAS CITY, ANNUAL ECONOMIC POLICY SYMPOSIUM, 2011. Disponível em: <https://www.kansascityfed.org/publications/research/escp/symposiums/escp-2011>. Acesso: 15 out. 2018.

ESCRIBANO, A.; FOSFURI, A.; TRIBÓ, J. A. Managing external knowledge flows: the moderating role of absorptive capacity. Research Policy, v. 38, p. 96-105, 2009.

GEREFFI, G. The organization of buyer-driven global commodity chains: how U.S. retailers shape overseas production networks. In: GEREFFI, G.; KORZENIEWICZ, M. (Eds.) Commodity chains and global capitalism. London: Greenwood Press, 1994, p. 95-122. 
GEREFFI, G. Shifting governance structures in global commodity chains, with special reference to the internet. American Behavioral Scientist, v. 44, n. 10, p. 1616-1637, 2001.

GEREFFI, G.; HUMPHREY, J.; STURGEON, T. The governance of global value chains. Review of International Political Economy, v. 12, n. 1, p. 78-104, 2005.

GEREFFI, G.; STURGEON, T. Global value chains and industrial policy: the role of emerging economies. In: ELMES, D.; LOW, P. (Eds.) Global value chains in a changing world. Geneva: WTO, 2013, p. 329-360.

GREENE, W. H.; HENSHER, D. A. Modeling ordered choices: a primer. Cambridge, MA: Cambridge University Press, 2010.

HAUSMANN, R. et al. The Atlas of Economic Complexity: Mapping Paths to Prosperity. Cambridge, MA, 2011.

HSIEH, W. L.; GANOTAKIS, P.; KAFOUROS, M.; Wang C. Foreign and domestic collaboration, product innovation novelty, and firm growth. Journal of Product Innovation Management, v. 35, n. 4, p. 652-672, 2017.

HUERTAS. G.; IRARRÁZAVAL, F. Regional opportunities: identifying promising local industries to improve Argentina’s economic complexity. Latin America Policy Journal, v. 8, p. 56-63, Spr. 2019.

HUMPHREY, J.; SCHMITZ, H. Governance and upgrading: linking industrial cluster and global value chain research. IDS Working Paper, n. 120, Nov. 2000.

HUMPHREY, J.; SCHMITZ, H. How does insertion in global value chains affect upgrading in industrial clusters? Regional Studies, v. 36, n. 9, p. 1017-27, 2002.

INCE, H.; IMAMOGLU. S. Z.; TURKCANA, H. The effect of technological innovation capabilities and absorptive capacity on firm innovativeness: a conceptual framework. Social and Behavioral Sciences, v. 235, p. 764-770, 2016.

JENSEN, M. B. et al. Forms of knowledge and modes of innovation. Research Policy, v. 36, n. 5, p. 680-693, 2007.

KLEVORICK, A. et al. On the sources and significance of interindustry differences in technological opportunities. Research Policy, v. 24, n. 2, p.185-205, 1995.

LAURSEN, K.; SALTER, A. J. The paradox of openness: appropriability, external search and collaboration. Research Policy, v. 43, n. 5, p. 867-878, 2014.

LEE, K.; SZAPIRO, M.; MAO, Z. From global value chain (GVC) to innovation systems for local value chains and knowledge creation. The European Journal of Development Research, v. 30, n. 3, p. 424-441, 2017.

LUNDVALL, B.-Å. (Ed.) National systems of innovation: towards the theory of innovation and interactive learning. London: Pinter Publishers, 1992.

LUNDVALL, B.-A. The origins of the national innovation system concept and its usefulness in the era of the globalizing economy. Aalborg: Aalborg University, 2015. [Paper prepared for presentation at the 13th Globelics Conference 2015 in Havana]

LUNDVALL, B-Å; JUROWETZKI, R.; LEMA R. Combining the global value chain and the innovation system perspectives. Aalborg: Aalborg University, 2014. [Paper prepared for the 11th Asialics International Conference 2014, in Daegu (Korea)] 
MALERBA, F. (Ed.) Sectoral Systems of Innovation - concepts, issues and analyses of six major sectors in Europe. Cambridge: Cambridge University Press, 2004.

MALERBA, F. Sectoral systems: how and why innovation differs across sectors. In: FAGERBER, J.; MOWERY, D.; NELSON, R. (Eds.) The Oxford Handbook of Innovation. Oxford: Oxford University Press, 2005, p. 380-406.

MEMEDOVIC, O.; IAPADRE, L. Structural change in the world economy: main features and change. Research and Statistics Branch Working Paper, UNIDO, n. 24, 2009.

MENTION, A. L. Co-operation and co-opetition as open innovation practices in the service sector: which influence on innovation novelty? Technovation, v. 31, n. 1, p. 44-53, 2011.

MILBERG, W.; WINKLER, D. Outsourcing economics: global value chains in capitalist development. Cambridge: Cambridge University Press, 2013.

MUROVEC, N.; PRODAN, I. Absorptive capacity, its determinants, and influence on innovation output: cross-cultural validation of the structural model. Technovation, v. 29, n. 12, p. 859$872,2009$.

NELSON, R. R. National innovation systems: the comparative analysis. New York: Oxford University Press, 1993.

PIETROBELLI, C.; RABELLOTTI, R. Clusters and value chains in Latin America: in search of an integrated approach. In: PIETROBELLI, C.; RABELLOTTI, R. (Eds.) Global value chains, clusters and SMEs in Latin America. Washington: IDB, 2006, p. 1-39.

PINTO, E.; FIANI, C.; CORREAA, L. M. Dimensões da abordagem da cadeia global de valor: upgrading, governança, políticas governamentais e propriedade intelectual. In: OLIVEIRA, I. T.; CARNEIRO, F. L.; SILVA FILHO, E. B. da (Orgs.) Cadeias globais de valor, politicas públicas e desenvolvimento. Brasília: IPEA, 2017, p. 49-86.

POWELL, W.; GRODAL, S. Networks of innovators. In: FAGERBERG, J.; MOWERY, D.; NELSON, R. (Eds.) The Oxford Handbook of Innovation. Oxford: Oxford University Press, 2005, p. 56-87.

PROCHNIK, V. (Coord.) La inserción de América Latina en las cadenas globales de valor. Montevideo: Red Mercosur de Investigaciones Económicas, 2010.

RIKAP, C. Innovation as economic power in global value chains. Revue d'Économie Industrielle, n. 163 , p. $35-75,2018$.

TETHER, B. S.; METCALFE, J. S. Services and systems of innovation. In: MALERBA, F. (Ed.) Sectoral systems of innovation - concepts, issues and analyses of six major sectors in Europe. Cambridge: Cambridge University Press, 2004, p. 287-321.

TETHER, B. S.; TAJAR, A. Beyond industry-university links: sourcing knowledge for innovation from consultants, private research organizations and the public science-base. Research Policy, v. 37, n. 6, p. 1079-1095, 2008.

TIMMER, M. P. et al. Fragmentation, incomes and jobs: an analysis of European competitiveness. Economic Policy, v. 28, p. 613-661, 2013.

UN, C. A.; ASAKAWA, K. Types of R\&D collaborations and process innovation: the benefit of collaborating upstream in the knowledge chain. Journal of Product Innovation Management, v. 32, n. 1, p. 138-53, 2015. 
UNCTAD - UNITED NATIONS CONFERENCE ON TRADE AND DEVELOPMENT. WIR13 - World Investment Report 2013. New York and Geneva: United Nations, 2013.

UNIDO - UNITED NATIONS INDUSTRIAL DEVELOPMENT ORGANIZATION. Industrial Development Report 2013. Viena: UNIDO, 2013.

VIOTTI, E. B.; MACEDO, M. M. (Orgs.) Indicadores de ciência, tecnologia e inovação no Brasil. Campinas: Ed. da UNICAMP, 2003.

WANG, Z. et al. Measures of participation in global value chains and global business cycle. NBER Working Paper, n. 23222, Mar. 2017.

WIRSICH, A.; KOCK, A.; STRUMANN, C; SCHULTZ, C. Effects of university-industry collaboration on technological newness of firms. Journal of Product Innovation Management, v. 33, n. 6, p. 708-725, 2016.

WTO - WORLD TRADE ORGANIZATION. Global value chain development report 2019: technological innovation, supply chain trade, and workers in globalized world. Geneva: WTO, 2019. 


\section{APÊNDICES}

Tabela A1 - Utilização de fontes de informações externas

\begin{tabular}{lccc}
\hline Número de fontes utilizadas & Frequência & Percentual & Percentual Acumulado \\
\hline 0 & 1460 & 39,6 & 39,6 \\
1 & 287 & 7,8 & 47,3 \\
2 & 327 & 8,9 & 56,2 \\
3 & 367 & 9,9 & 66,1 \\
4 & 367 & 9,9 & 76,1 \\
5 & 294 & 8,0 & 84,0 \\
6 & 249 & 6,8 & 90,8 \\
7 & 136 & 3,7 & 94,5 \\
8 & 105 & 2,8 & 97,3 \\
9 & 60 & 1,6 & 98,9 \\
10 & 39 & 1,1 & 100,0 \\
Total & $\mathbf{3 6 9 1}$ & $\mathbf{1 0 0 , 0}$ & \\
\hline
\end{tabular}

Fonte: Elaboração própria com base em ENDEI (ARGENTINA, 2015a).

Tabela A2 - Proporção de engenheiros na força de trabalho

\begin{tabular}{lccccc}
\hline Variável & Observações & $\begin{array}{c}\text { Média } \\
\text { (\%total) }\end{array}$ & $\begin{array}{c}\text { Desvio } \\
\text { Padrão }\end{array}$ & Min. & Max \\
\hline prop_eduin2010 & 3691 & 21,5 & 32,8 & 0 & 100 \\
prop_eduin2011 & 3691 & 21,7 & 32,6 & 0 & 100 \\
prop_eduin2012 & 3691 & 21,8 & 32,5 & 0 & 100 \\
prop_engenheiro (2010-2012) & 3691 & 21,6 & 32,0 & 0 & 100 \\
\hline
\end{tabular}

Fonte: Elaboração própria com base em ENDEI (ARGENTINA, 2015a). 